\title{
Entre mundos: homens, serpentes e peixes em dois mitos baniwa
}

\author{
Gabriel Albuquerque ${ }^{1}$
}

Luiza Garnelo ${ }^{2}$

\section{Relações entre mito e literatura}

As relações estabelecidas entre mito e literatura são clássicas e se pode pensar que a reflexão sobre essa díade seja superada, pois, à primeira vista, tudo que se podia dizer já foi dito. Mas será assim mesmo? É Ernest Robert Curtius quem esclarece: “a mitologia é um produto tardio, e o caminho para o politeísmo é um progresso cultural. A fantasia, forjadora de ficções e mitos, existe para 'fabricar' espíritos e deuses" (Curtius, 1996, p 39). A afirmação do crítico alemão demonstra que ainda há muito o que se pensar sobre as relações entre mito e literatura uma vez que "a mitologia é um produto tardio". E, mais forte que isso, se nos detivermos no legado grego, é a literatura que registra e guarda o saber mítico, "pois como diz Heródoto, Homero e Hesíodo deram seus deuses aos gregos" (Curtius, 1996, p 39). Considerando que Hesíodo e Homero legam ao Ocidente grande parte dos seus mitos a partir da Ilíada, da Odisséia e da Teogonia, o que nos deu muito da cultura literária renascentista e pós-renascentista, cabe pensar, superada essa fase da cultura ocidental, o que foi feito dos mitos recolhidos pelos viajantes e demais escritores quando estes começam a descobrir as Américas uma vez que, a partir desse acontecimento histórico, o Ocidente incorpora e inventa o Novo Mundo.

No seu Amazônia: mito e literatura, Marcos Frederico Krüger Aleixo abre a discussão sobre o tema lembrando as origens do romance Macunaíma, de Mário de Andrade, ou seja, a origem do herói sem nenhum caráter está em Von Roroima zum Orinocono, do viajante alemão Theodor Koch-Grumberg. Há vários escritos sobre como Mário de Andrade se apropriou do mito de Macunaíma para criar o romance, um símbolo do modernismo brasileiro, e a discussão parece fechar-se aí para a crítica especializada, porém a questão é mais ampla e carece de debate.

\footnotetext{
${ }^{1}$ Doutor em letras e professor da Universidade Federal do Amazonas (Ufam), Manaus, AM, Brasil. E-mail: g_albuquerque@ufam.edu.br

${ }^{2}$ Doutora em ciências sociais/antropologia e professora do Instituto Leônidas e Maria Deane, da Fundação Oswaldo Cruz (Fiocruz), Manaus, AM, Brasil. E-mail: luiza.garnelo@ fiocruz.br
} 
No Amazonas, são poucos os escritos sobre os mitos produzidos pelos povos indígenas, em que pese a multiplicidade de culturas aqui existentes. Conta-se com o que foi feito por João Barbosa Rodrigues (Poranduba amazonense, 1890), por Antônio Brandão de Amorim (Lendas em nheengatu e português, 1928), pelo etnólogo Nunes Pereira (Moronguetá, um Decameron indígena, 1967).

Destaque deve ser dado às publicações dos próprios indígenas, iniciando-se pela obra pioneira de Umúsin Panlõn Kumu e Tolamãn Kenhíri (Antes o mundo não existia, 1980), organizada por Berta Ribeiro. Esse esforço inicial redundou em diversas publicações subsequentes, como a de Ismael e Ângelo Moreira (Mitologia Tariano, 1994) e os oito volumes da Coleção Narradores Indígenas, publicados pela Federação das Organizações Indígenas do Rio Negro (Foirn), em associação com o Instituto Socioambiental (ISA), no período compreendido entre 1990 a 2004. Essa coleção contou com intenso trabalho de organização de antropólogos como Dominique Buchillet, Geraldo Andrello e Robin Wright. Este último é responsável pela publicação da primeira coletânea que reuniu alguns mitos baniwa (Waferinaipe Ianheke: a sabedoria dos nossos antepassados - Histórias dos Hohodene e dos Walipere-Dakenai do rio Aiari, 1999), no volume 3 da Coleção Narradores Indígenas do Rio Negro.

Num plano mais teórico, mas também voltadas para a mitologia do noroeste amazônico, as publicações de Robin Wright (Umawali. Hohodene myths of the Anaconda, father of fish, 1993-94) e de Hill \& Wright (Rethinking History and Myth, 1988), ainda que pouco acessíveis ao leitor brasileiro, representam marcos importantes na condução de estudos de etnologia nessa área da cultura.

Após pequeno hiato temporal, veio a público a coletânea de mitos indígenas denominada Cultura, escola, tradição: mitoteca na escola baniwa (Garnelo et al., 2005), ${ }^{3}$ que também foi a primeira coletânea organizada, no alto rio Negro, em torno de um tema específico, ou seja, os animais, ambientes aquáticos e as artes de pesca. A partir do material coletado para o livro, resultante do projeto com o mesmo nome, verificou-se estarmos diante de um manancial de possibilidades interpretativas.

\footnotetext{
${ }^{3} \mathrm{O}$ projeto Mitoteca na escola Baniwa foi uma pesquisa participante, desenvolvida pelos autores em conjunto com a escola Pamaali, uma escola indígena assentada no médio Rio Içana, Noroeste amazônico. O projeto contemplou a coleta de mitos relativos aos ambientes aquáticos e seus habitantes, resultando, entre outros produtos, na publicação do registro escrito e de áudio (em língua indígena) de um grande acervo de narrativas sobre o tema, formando uma verdadeira biblioteca de mitos, o que justifica a designação de "mitoteca".
} 
Contudo, por que voltarmos a esses mitos uma vez que interessam especialmente aos povos que os produziram? Uma resposta possível está nas palavras de Angela Carter, organizadora da antologia 103 contos de fadas, para quem "ao longo da maior parte da história humana, 'literatura', tanto prosa como poesia, era algo contado, não escrito ouvido, não lido". Assim, os contos de fada, os contos populares, as histórias da tradição oral constituem a mais vital ligação que temos com o universo da imaginação de homens e mulheres comuns, cujo trabalho criou o mundo (Carter, 2007, p. 13).

Antes que os leitores se armem diante das diferenças entre gêneros (contos de fada, contos populares, narrativa oral e mitos), deve-se dizer que temos clareza de que as narrativas míticas dos Baniwa não estão na mesma categoria dos contos de fada. Contudo, há elementos constitutivos dessas variedades narrativas que são recorrentes a todas as narrativas orais: o caráter moralizante, a interveniência de entes mágicos, as fronteiras entre o mundo de humanos e não humanos, a explicação para o surgimento de um acidente geográfico ou de uma prática humana (religiosa, de trabalho, da cultura) e a presença de um herói que, para os Baniwa, é Napirikoli. Quanto ao trabalho de coleta dos mitos tal qual feito durante a pesquisa que gerou o livro Cultura, escola, tradição: mitoteca na escola baniwa (2005), o que Zumthor (1993, p 18) determina como oralidade primária e imediata constitui-se como a origem dos dados. A língua em que os mitos baniwa são registrados é ágrafa em princípio. Diante disso, as narrativas foram gravadas por estudantes baniwa que procederam a uma primeira versão escrita para a língua portuguesa e, posteriormente, essa versão inicial passou por um tratamento constituído por revisão e adequação de termos e estruturas próprios da língua portuguesa. Os procedimentos de registro, coincidindo a comunicação (feita pelos narradores) e a recepção (feita pelos estudantes baniwa), manifestam-se como performance (Zumthor, 1993, p 19), cuja execução poderá ser atualizada à medida em que as narrativas voltam a ser recitadas cumprindo, para além da fruição, também uma função ritual.

Se aceitarmos os argumentos apresentados por Angela Carter, os mitos narrados pelos Baniwa são como a literatura em estado puro, antes da imprensa, antes do papel, antes da escrita, antes da leitura. Ao vertermos os mitos coletados por estudantes baniwa para a forma de livro, inicia-se um processo no qual é possível dar a conhecer como essa 
etnia concebe o surgimento de determinadas espécies animais, como os peixes e os quelônios, mas também como os Baniwa se relacionam entre si e com o mundo que os cerca, como concebem e organizam esse mundo. Há, portanto, um valor bastante alto na leitura que se faz desses mitos e que pode ser compreendida como as duas faces de uma moeda: de um lado, os mitos simbolizam as forças que moldam as origens do mundo e dos seres que nele habitam e, de outro, possibilitam o entendimento processual de comunidades que encontraram no Alto Rio Negro um lugar para proteger a si e a sua cultura. Outro argumento de Carter vale ser conhecido: "à medida que o passado fica cada vez mais diferente do presente, distanciando-se ainda mais rapidamente nos países em desenvolvimento do que nos desenvolvidos, industrializados, precisamos saber quem fomos de maneira mais precisa, para poder conceber o que haveremos de ser" (Carter, 2007, p 14).

Em outras palavras, ao interpretarmos os mitos baniwa, estamos fazendo uma averiguação das origens amazônicas e brasileiras ao mesmo tempo em que, registrando as variantes dos mitos, apontamos como a presença do homem branco incide sobre diferentes aspectos da cultura baniwa, sobre o futuro daquela etnia e dos saberes tradicionais por ela guardados. Esses saberes são fundamentalmente transmitidos pelas narrativas orais e entre os vários mitos coletados para a mitoteca baniwa, dois foram selecionados para a leitura que propomos: Origem de Bacaba-Poço e cabeçudos e Hiwidamitti e origem dos peixes.

\section{Por que escolhemos os dois mitos aqui relacionados?}

As discussões que estabelecemos para chegar aos mitos capazes de dar abertura para interpretações mais amplas apontavam para questões fundamentais, não só para os Baniwa como para todos os homens: os limites entre humano e não humano, o estabelecimento de regras de convivência entre os sujeitos de uma mesma comunidade, a sobrevivência frente aos limites impostos pela natureza, o respeito devido aos que criam as regras de convivência e as relações entre trabalho e produção de alimentos (Garnelo, 2007; Garnelo; Diniz e Sampaio, 2012)

Ainda que sob formas diversas, essas questões são postas nos dois mitos. No primeiro deles e suas variantes, que trata da Origem de BacabaPoço e cabeçudos, narrado por Alberto Lourenço, verifica-se que se trata de um mito que narra mais do que a origem de um lugar e sua 
nomeação (valor etiológico), mas lida também com o surgimento de seres vários e o modo pelo qual esses animais (o cabeçudo e outros quelônios, os sapos e as rãs) apareceram na natureza.

Já a completude do segundo mito, intitulado Hiwidamitti e origem dos peixes, torna-se mais evidente quando analisamos as diversas versões - Hiwidamitti e origem dos peixes (outra versão); a História do homem que perdeu partes do corpo; e a Origem dos peixes que pulam -, pois onde uma omite certa informação, outra esclarece.

Essas variantes deixam claro que há diversos modos de narrar para os Baniwa, considerando que as versões podem ser alongadas ou breves, mais ou menos explicativas. E podem ainda revelar o estilo do contador, conforme este se dedique a detalhar as descrições ou deixe que o ouvinte/leitor complete sentidos e interprete símbolos. Nas duas versões do mito de Hiwidamitti narradas por Valentim Paiva, não encontramos qualquer definição para o que sejam os Iñaime; contudo, na narração feita por Lúcio Paiva, os Iñaime são definidos como "diabos". Esse é um pequeno exemplo do que podemos encontrar na diversidade das variantes. E se há essa diversidade, é sinal de que o mito de Hiwidamitti tem significação forte para os Baniwa muito embora não possamos delimitar e apreender essa significação em sua totalidade.

Enquanto no mito Hiwidamitti e a origem dos peixes prevalece a temática das relações entre humanos e não humanos e as consequências para quem desrespeita as fronteiras entre esses dois modos de existência, em Origem de Bacaba-Poço e cabeçudos prevalece um arranjo complexo que não diz respeito apenas às ações das personagens envolvidas, mas ao modo como essas personagens desdobram-se em outros seres. Temos, portanto, nesse mito, uma espécie de enquadramento com histórias dentro de histórias, o que iremos explorar mais adiante.

\section{Comentários sobre Hiwidamitti e Origem de Bacaba-Poço}

Um dos elementos essenciais à leitura que se faz de mitos é o modo como eles se completam e se esclarecem mutuamente; tal característica é apontada por Lévi-Strauss (1975) como um dos elementos estruturais do pensamento mítico. $O$ autor ressalta a capacidade dos mitos de transmutarem suas unidades constitutivas umas nas outras, observandose a combinação e recombinação de seus elementos conceituais, sem haver alteração essencial em sua estrutura (Lévi-Strauss, 1993a). O autor também alerta que "o significado básico do mito não está ligado à 
sequência de acontecimentos, mas antes, se assim se pode dizer, a grupos de acontecimentos, ainda que eles possam ocorrer em momentos diferentes da História" (1978, p. 68). Assim sendo, raramente um mito pode ser compreendido por si só, exigindo a análise de conjuntos de outros mitos e sempre ambicionando alcançar explicações globais sobre a vida e universo humanos (Lévi-Strauss, 1993b).

É o que vemos, a título de exemplo, quando na famosa passagem de Dionísio por Tebas, o deus do vinho provoca a queda da família de sua tia Ágave. Mas o que teria havido para que se desse a morte violenta de Penteu, filho de Ágave e primo de Dionísio, sem que o deus do vinho nada fizesse para evitar a tragédia? Acontece que Dionísio não perdoa "as irmãs de sua mãe, as filhas de Cadmo, e sobretudo Ágave, por terem afirmado que Sêmele nunca teve relações com Zeus, que não passava de uma histérica cujos amores eram suspeitos, que morreu em um incêndio por sua imprudência e que se tivesse tido um filho, este teria desaparecido" (Vernant, 2005, p 153). Eis a explicação para os ressentimentos familiares de Dionísio; afinal ele não é reconhecido como deus e nem como parte da família humana de que nasce. Essa passagem do mito é que dará origem à tragédia $A s$ bacantes, de Eurípedes. Da mesma forma, o mito de Macunaima deu origem ao romance homônimo.

A relação estabelecida entre diferentes narrativas não é uma especificidade dos gregos. Condição similar pode ser observada nos mitos baniwa que aqui analisamos. Ao lidarmos com o mito de Hiwidamitti, logo se percebe que os malokoalinai (Iñaime) são seres advindos de outra esfera ou ciclo de mitos. Ao lermos Origem de Bacaba-Poço, vemos que há, na versão narrada por Alberto Lourenço, indícios que apontam para outros mitos, pois não se trata apenas da origem dos peixes, mas do modo pelo qual, tendo vivido no fundo da água sob a guarda de uma "pessoa-sucuriju", como define Lúcio Paiva em sua versão do mito, o menino que se tornará o "avô dos cabeçudos" é agora um ser cindido, pois resulta do encontro entre dois mundos: humano e não humano; aquático e terrestre. O mesmo é válido para Hiwidamitti: ele também entrou em contato com um mundo diferente ao desrespeitar os limites que separam os homens e os Iñaime, que são, afinal, os espíritos vagantes de mortos que não alcançaram seu local de repouso final. 


\section{O primeiro mito: Origem de Bacaba-Poço e Cabeçudos}

Para ampliar a questão, cabe uma síntese do mito "Origem de BacabaPoço e Cabeçudos" tal qual é narrado por Alberto Lourenço: o outro nome de Bacaba-poço é Poperiana. Há muito tempo, lá vivia um homem que fabricava peixes, chamava-se Omawali, na versão de Alberto Lourenço, e Koyaweno, na versão de Valentim Paiva. ${ }^{4}$ Essa pessoasucuriju tinha por ofício fabricar ralos e, dos pedaços da madeira que sobravam da feitura dos ralos e caiam na água, nasciam peixes. Acontece que "no tempo dos antepassados, algumas pessoas quiseram ver Omawali" e, para tanto, comeram alimento estragado e foram a Poperiana, pois, ao comer alimentos estragados, é possível ver a serpente Omawali. Tendo conseguido ver o fabricante dos peixes, essas pessoas retornaram de Poperiana e contaram aos demais que lá vivia o "carpinteiro dos peixes". Nesse ponto da versão de Alberto Lourenço há um hiato e é como se uma nova narrativa se iniciasse sem ter a ver com a que lhe antecedia. Esse é um recurso comum às narrativas orais, uma vez que não contam com os mesmos recursos empregados nas formas canônicas da narrativa. Na mesma passagem, mas em outra versão do mito, contada pelo mesmo narrador, diz-se que um homem, "um antepassado", desafia a proibição de passar por um trecho do rio próximo ao lago em que vive a serpente Omawali; ao insistir em passar por ali de canoa, tem o filho raptado e com a ajuda de um boto, vai ao mundo do "carpinteiro de peixes" para resgatá-lo. Nessa aventura, o antepassado mata Omawali, retorna com o filho ao mundo dos homens, mas irá perdêlo para a natureza uma vez que o menino não mais conseguirá se adaptar à vida dos homens. Ele será o avô dos cabeçudos e ordenará o lugar e o fazer de vários seres na natureza, que como ele, transitam entre ambientes aquáticos e terrestres: cabeçudos, jabutis de variado tamanho e o aara (uma espécie de quelônio não classificada em língua portuguesa).

\footnotetext{
${ }^{4}$ Cabe esclarecer que as versões recolhidas tanto expressam variantes de narrativas reconstruídas segundo a experiência e conhecimento do narrador, quanto versões frátricas, já que um narrador como Valentim narra versões da fratria Dzawinai, ao passo que Alberto Lourenço tanto conhece, e narra, variantes oriundas do sib mawlieni, fratria Hohodene, quanto do sib walipere dakenai, fratria Walipere, todos componentes do sistema baniwa de parentesco.
} 
A história do avô dos cabeçudos, como narrada por Alberto Lourenço nas duas versões, é intercalada pelas referências às características dos quelônios cuja origem também é contada neste mito. Numa delas, narrase como um tipo de cabeçudo, o quelônio aarheni paitsi ipiraita é o mestre de dança no mundo das rãs, mas o propósito desse quelônio é, na verdade, alimentar-se dos ovos das rãs. O mito se encerra com a partida de rãs e cabeçudos após a piracema, aqui comparada a uma dança.

Tão rica que é, essa narrativa aponta em várias direções, pois diz respeito a um lugar, Bacaba-Poço, no qual nasceram os peixes, e ao criador dos peixes, uma pessoa-sucuriju. Comecemos pela ideia de que um ser mítico, a serpente Omawali, é o "carpinteiro dos peixes". Tratase de uma imagem clássica na qual o demiurgo é um artífice. Na mythopeia platônica, demiurgo é o criador que ora aparece como artífice, fazedor de coisas e seres, ao lado do qual há uma Natura artifex e, para Curtius, "o artificum de ambos é o mesmo: criação do mundo e do homem, arquitetura, cerâmica, ourivesaria e ocasionalmente, também pintura" (Curtius, 1996, p. 665). Ao que tudo indica, seja Deus, seja a Natureza, o ato de criar é um fazer com as mãos e é essa exatamente a ocupação de Omawali: ele é um fazedor porque produz com as mãos os ralos empregados nas atividades cotidianas, especialmente na produção de alimentos derivados da mandioca.

Embora não tenha criado os homens, Omawali é o criador de seu principal alimento, o peixe. Mas é uma serpente, um ente mítico cuja força é dúbia, representando não só perigo, como também inteligência, perspicácia. Só com o recurso a outras narrativas que não as que aqui selecionamos, pode-se saber que as grandes serpentes, das quais Omawali é um dos representantes, são inimigas mortais dos deuses criadores da humanidade e desejam a todo custo exterminar essa descendência, isto é, a nós. Tal informação dá a devida dimensão ao ato de desafio do antepassado que insiste em passar de canoa pelos domínios do artesão de peixes. Sem oferecer maiores detalhes de tal subtexto ao narrar, Alberto Lourenço diz que "algumas pessoas" queriam ver o carpinteiro de peixes. Mas queriam vê-lo com que interesse? Isso não nos é explicado. Porém, quando o antepassado vai à busca do filho no mundo de Omawali, parece ter um conhecimento prévio daquele mundo. E isto se dá não apenas pelas informações que o boto, seu auxiliar, passou, mas por uma espécie de conhecimento prévio que as pessoas daquele tempo mítico pareciam ter sobre o 
mundo das serpentes. É somente pela busca de outro segmento na "terra redonda dos mitos", como diria Lévi-Strauss (1978), que poderíamos saber sobre a coexistência conflituosa entre os ancestrais da humanidade e as grandes serpentes, sistematicamente assassinadas pelos antepassados míticos para que os homens pudessem prosperar como espécie dominante nesta terra. A morte de Omawali gera, porém, uma importante consequência para a descendência humana: uma drástica redução da potencialidade reprodutiva dos peixes, uma habilidade que era monopólio das serpentes. $\mathrm{O}$ ato de criação, cuja potência não cabe no domínio humano, perde-se para sempre, o que explica, no entendimento baniwa, a razão da escassez de peixes em seu ambiente aquático, o Rio Içana.

\section{Caxiri, piracema e dança}

Para os mitos baniwa, os animais são pessoas no mundo em que habitam, mas somos nós, em nosso mundo, que os vemos como animais. Essa distinção entre o mundo dos animais e o mundo dos homens não significa uma separação absoluta de domínios; pelo contrário, o que se verifica nas narrativas é que, embora diversos, homens e animais se comportam como pessoas que partilham muitos traços comuns de práticas próprias aos homens, ainda que reproduzidas no mundo dos animais: quando o antepassado vai ao mundo de Omawali para recuperar o filho, encontra uma aldeia onde houve festa e se tomou caxiri. Há a casa das mulheres e são elas que servem a bebida enquanto Omawali descansa após embebedar-se.

As situações contidas nas narrativas remetem, de modo inequívoco, às ideias sobre o perspectivismo, desenvolvidas pelo antropólogo Eduardo Viveiros de Castro (1996; 2002). Para o autor, o pensamento ameríndio é permeado por uma ontologia que reconhece a condição de sujeito tanto para seres humanos, quanto para não humanos, partilhando ambos a condição de pessoas dotadas de intencionalidade e volição. Nessa ontologia, humanos, animais e outros entes supra-humanos partilhariam uma unidade de espírito em contraponto a uma variada corporalidade (zoomórfica e antropomórfica, com inúmeras variações para cada ser). As distinções corporais ${ }^{5}$ propiciariam a chave para o entendimento de como

\footnotetext{
${ }^{5}$ Viveiros de Castro caracteriza o corpo como "um feixe de afecções", ou seja, a corporalidade é descrita como um conjunto de capacidades e comportamentos típicos de um ser, uma concepção
} 
pessoas humanas e não humanas se assemelham, mas nunca são exatamente iguais, logrando manter irredutível a distinção que caracteriza a relação do Eu com a alteridade. Nela, o interdito da dissolução do Eu no Outro é a base da preservação da vida social (Castro, 2002).

Como se observa na mitologia aqui analisada, a interação entre os sujeitos se efetua, mas se institui sempre em momentos extraordinários, tendo como resultado a transformação irredutível dos corpos que adentraram o domínio do não humano. É o que se pode ver, por exemplo, na teimosia do humano que desafia os domínios de Omawali - insistência que redunda na perda de seu filho, raptado pelo animal - e no descuido da serpente raptora, cuja embriaguez permite que o humano a mate e recupere a criança raptada. Ainda que, à primeira vista, tudo pareça resolvido, nada retorna à condição inicial. A morte da serpente inviabiliza a continuidade da reprodução dos corpos de peixes que alimentam os humanos, e a criança resgatada mostra-se incapaz de conviver normalmente com sua família humana, passando a buscar compulsivamente o meio aquático. Seu corpo transmutado pela permanência na aldeia subaquática a torna apta a se converter no criador (o "avô") dos quelônios, até então inexistentes neste mundo, mas a afasta da condição plenamente humana.

Ressalte-se que a prática do rapto não é incomum aos mitos. J. P. Vernant explica, ao narrar o rapto de Europa por Zeus (Vernant, 2005, p. 147), que os raptos são uma das formas de se passar de um mundo a outro. No caso do rapto do menino por Omawali, esse ato se justifica pelo fato de o pai haver transposto um limite ao aventurar-se por um lugar perigoso, Poperiana, onde a serpente vivia.

Outro importante estudioso das relações entre humanidade e natureza nas culturas ameríndias é o antropólogo francês Phillippe Descola (2001). Este autor tem certas restrições ao perspectivismo, mas aceita a ideia de que, segundo o ponto de vista das sociedades indígenas americanas, a diferença entre homens, plantas e animais seria mais de grau (das características de cada um) que de natureza do ser. Entretanto, Descola (2001) prioriza o olhar sobre a lógica que rege as relações entre os sistemas cosmológicos e sociológicos produzidos pelas sociedades ameríndias com a natureza, caracterizando-as como uma teia de relações

que transcende, em muito, a noção de senso comum que restringe os corpos à dimensão biológicomaterial (Castro, 2002). 
sociais que tanto comporta aliança e reciprocidade, quanto agressividade e predação. Nesse sentido, o domínio da alteridade - como a aldeia de Omawali e o igarapé dos Inãime onde Hiwidamitti pesca - é sempre terreno perigoso, onde a obtenção de elementos que permitem reproduzir a vida humana pode custar a própria condição humana dos que traspassam as fronteiras entre mundos.

Ainda que assemelhadas à primeira vista, as situações cotidianas apresentadas nos mitos que aqui analisamos não são exatamente iguais às humanas. Se tomarmos como exemplo das ocupações dentro da comunidade, na narrativa de Omawali, o quelônio aara é apresentado como mestre de dança. Já a piracema das rãs compara-se a uma festa semelhante às festas dos homens. Em outros mitos os narradores dizem que foi no mundo dos peixes que os homens aprenderam a fazer festas com danças, insistindo-se na possibilidade de transmutação de um mundo em outro. Entretanto, os narradores assinalam que "ele (o aara) começou a dançar com elas (as rãs); rodava no meio da comunidade, mas não era bem uma comunidade; na verdade, o local da festa era um lago". Ou seja, embora haja similitude e paralelos entre os mundos do homem e dos animais, não são mundos iguais; tal distinção aparece na ressalva "mas não era bem uma comunidade". Também aqui a teoria do perspectivismo pode ser bem aplicada, na medida em que nela se preconiza que a diferenciação de corpos resulta, inclusive, em diferença de perspectivas. Tal distinção expressa-se, ainda, como um campo intersubjetivo, que congrega humanos e animais, ainda que cada um dos sujeitos dessa relação possa assumir uma perspectiva simétrica, mas invertida, na apreensão que faz do Outro. Nos mitos aqui analisados, a comunidade das serpentes é, do ponto de vista humano, um lago, e as rãs dançam como nas festas humanas, mas o narrador identifica claramente que a festa é, na verdade, uma piracema - ou seja, a organização dos modos de vida é entendida como parecida com a existência humana, mas nunca integralmente igual (Castro, 1996).

Embora não se possa comparar o emprego dos verbos em baniwa e em português, a tradução das narrativas feita pelos estudantes baniwa traz os verbos no pretérito imperfeito ("as rãs diziam que o aara era muito engraçado", "falavam que gostavam da dança dele", "havia outro avô das rãs" etc.), indicando não só o tempo primordial mas também que o efeito do mito ainda não terminou, que é o que se espera do tempo mítico: simultaneamente passado e presente. Esse desdobramento dos efeitos do 
mito comprova-se especialmente na existência dos lugares: Bacaba-Poço, no mito que ora se lê; Mitu e Hipolecoa, no mito de Hiwidamitti. Os lugares servem para comprovar a veracidade do que foi narrado e, em alguns casos, justificam a existência deles e demarcam os eventos extraordinários lá ocorridos.

É perfeitamente compreensível que, se o mundo dos homens se ordena em uma série de lugares, o mesmo é válido para o mundo dos animais; e se o mundo dos homens se organiza pelo trabalho, pelo ciclo de festas e pelos hábitos alimentares, isso também é válido para as pessoas-animais, desde que atendidas as supracitadas ressalvas atribuídas ao enfoque perspectivista ameríndio. Outra distinção observada é que, se no mundo dos homens é por meio do trabalho que se transforma a natureza (o ralo serve para transformar a mandioca em alimento), na esfera do mito, o trabalho é substituído por um ato mágico. Assim é que as lascas de madeira que sobram dos ralos feitos por Omawali transformam-se em peixes.

\section{O segundo mito: Hiwidamitti}

As quatro narrativas que contam o surgimento dos peixes a partir da personagem Hiwidamitti permitem aproximações com o mito de Omawali. Mas antes de estabelecer essas aproximações, é conveniente informar alguns acontecimentos que se dão nas quatro variantes: i) a narrativa mítica se inicia quando dois irmãos vão pescar em um local onde estavam os Iñaime (também chamados malokoalinai em referência ao igarapé Malokoali); ii) o irmão mais velho, ao se distanciar para procurar por peixes, deixa o mais novo com a recomendação de que não se aproxime nem aceite nada dos Iñaime; iii) os Iñaime pedem que o irmão mais novo os leve ao outro lado do igarapé e, em sinal de agradecimento, dão a ele peixe moqueado, com uma ressalva: cozer bem o alimento senão se tornará igual aos Iñaime; iv) o irmão mais novo não só desobedece ao mais velho como desobedece também aos Iñaime, perdendo partes do corpo que, ao caírem na água transformam-se em peixes; v) do irmão mais novo resta apenas a cabeça, um parasita que se alimenta de tudo até quase matar o irmão mais velho; e vi) o irmão mais velho se vê livre da cabeça, Hiwidamitti, que cai em um lugar ermo, chamado Poço Fervendo e talvez ainda viva por lá. Em uma das variantes, a cabeça morre ao cair em um chão de pedra. 
A história de Hiwidamitti é uma das primeiras a ser contada quando se pergunta como os peixes surgiram no mundo, o que atesta sua importância entre os Baniwa. As versões da narrativa apresentam algumas sutis variações entre si e, ainda que não tenhamos alteração significativa no encadeamento básico dos eventos, certos elementos permitem aclarar nuances envolvidas na interação entre o personagem humano e os Iñaime.

Em primeiro lugar, cabe assinalar que Hiwidamitti não é o nome do personagem. Esse não surge nas narrativas com um nome próprio, e só se torna Hiwidamitti, um termo traduzido por alguns como "cabeça de moqueado" e por outros como guloso ou comilão, após perder importantes características humanas devido à redução de seu corpo a uma cabeça voraz e antissocial, cujos desejos e necessidades tiranizam seus consanguíneos.

Tais características de personalidade expressavam-se sutilmente no modo de ser do - ainda humano - irmão mais novo, em cujo comportamento se pode ler o prenúncio de transgressões consideradas altamente condenáveis na ética baniwa. Atos que ameaçam a vida em sociedade, como gulodice, mentira, teimosia, curiosidade excessiva, desobediência aos mais velhos, avareza e recusa em partilhar os alimentos, são perpetrados em rápida sequência, por alguém cuja vida, até então, passava-se de modo ordinário.

Alguns narradores denominam os Iñaime de "espíritos maus", mas o texto mítico traz uma importante inversão: nas narrativas, o comportamento desses seres é cordato e educado: eles pedem a Hiwidamitti o favor de atravessá-los em sua canoa para o outro lado do igarapé; eles atendem ao guloso Hiwidamitti quando ele pede peixe moqueado como pagamento pela travessia e, mais do que isso, eles avisam o que poderia acontecer ao jovem caso consumisse os peixes pescados pelos Iñaime e informam que procedimentos devem ser tomados, para que o peixe possa ser comido sem oferecer perigo. Nas quatro variantes, $o$ comportamento antissocial é o do humano, que extorque e ameaça os espíritos para que atendam a seus insistentes pedidos por comida: impulsivo, ignora os prudentes conselhos que recebe e devora rapidamente todo o alimento sem guardar nada para o irmão.

A destruição das características físicas de um ser humano e da possibilidade de contribuir para sua subsistência e a de seus consanguíneos aprofunda as tendências antissociais da cabeça, atingindo um grau de paroxismo que ameaça destruir inclusive a vida de seu provedor (o irmão mais velho sobre o ombro do qual a cabeça 
enraizou-se). A exacerbação desse comportamento parasita propicia ao irmão a possibilidade de livrar-se de vez de Hiwidamitti, ao estimular a própria gula do incômodo ser e obter por fim o seu extermínio.

A convivência nas aldeias baniwa mostra rapidamente ao forasteiro que, ali, um dos comportamentos considerados mais relevantes para a manutenção da vida social é a partilha dos alimentos. As refeições coletivas, que representam um dos pontos altos da vida cotidiana, concretizam esse princípio, mediante a obrigação de cada família em contribuir para as refeições distribuídas diariamente a todos os presentes no salão comunitário (Garnelo, 2009). A esse princípio de reciprocidade obrigatória adiciona-se a forte censura ao ato de pedir comida; até as crianças pequenas são brandamente repreendidas quando o fazem, dado que a oferta deve partir sempre daqueles que dispõem do alimento. Nesse contexto, o teor moral contido na história de Hiwidamitti ganha inteligibilidade também como parte das estratégias de socialização das novas gerações (Garnelo, 2009).

Tanto no mito de Omawali quanto no de Hiwidamitti, há evidentes proximidades que podemos interpretar como pertencentes a um mesmo sistema. Em primeiro lugar está a passagem dos homens por locais proibidos ou não recomendados, cujo pertencimento ao domínio da alteridade ameaça a vida humana ou a transforma de modo radical e, não raro, irreversível. No mito de Omawali, o pai perde o filho ao arrastar a canoa por um lugar perigoso, Bacaba-Poço, pois lá vivia a serpente. Já no mito de Hiwidamitti, os dois irmãos vão pescar num local definido nas palavras do narrador Valentim Paiva como um "local proibido". A que se deve a interdição do lugar senão à presença dos Iñaime? É de se imaginar que determinados lugares da geografia mítica dos Baniwa tenham um caráter liminar, confluindo entre o mundo dos humanos e dos não humanos. A transposição desse limite sem o atendimento a cuidados rituais adequados levará, fatalmente, a uma perda, total ou parcial, da condição humana. São os parentes que perguntam ao homem que perdeu o filho no Bacaba-Poço "por que tu passaste nesse local?", e é o irmão mais velho que diz ao mais novo para permanecer na canoa e não se aproximar dos Iñaime. Em segundo lugar - e esse é um elemento essencial ao mito -, do ato de desrespeito à interdição é que nasce a narrativa, seu ensinamento e, normalmente, um bem. Das partes do corpo de Hiwidamitti nascem peixes. Com a morte de Omawali, domina-se o Bacaba-Poço e se recebem os cabeçudos como alimento. As noções de 
bem e mal estão aqui enoveladas, pois acontece uma espécie de reversibilidade: o que era em princípio uma perda torna-se um ganho.

Na busca de uma convergência entre os dois mitos, pode-se pensar no lugar comum entre ambos, que é a origem dos peixes. No caso de Omawali, temos um deus artífice na forma de uma serpente (Omawali é um deus-serpente, rival do deus dos humanos, Napirikoli). Já em Hiwidamitti, temos a transgressão de um humano que gera um bem maior. Para os dois personagens, a contrapartida a tal benefício é sua completa destruição. Contudo, em ambos os casos, fica sempre o caráter moralizante, pois não se deve ir a determinados lugares sem respeitar o que já foi estabelecido, não se deve explorar o outro nem colocar dois diferentes mundos em contato sem esperar as consequências desse ato.

\section{Inclusões, considerações, possibilidades}

As narrativas míticas têm, enfim, uma função múltipla na pretensão de preservar os conhecimentos tradicionais e o idioma em que foram criadas, ao revelar para os leitores e ouvintes um pouco do que já foi dito por Angela Carter: quem somos e quem haveremos de ser.

Somos hoje, uma nação múltipla, diversa e, em grande parte, desconhecida de si mesma, daí podermos situar a ocorrência de manifestações literárias (orais e escritas) em condição insular (Albuquerque, 2009), sendo este o caso das narrativas míticas baniwa. Se considerarmos os mitos aqui apresentados como matéria preservada na oralidade e vertida para a escrita, temos o registro de um conhecimento milenar que se abre para diferentes interpretações: inicialmente, no campo da antropologia e, mais tardiamente, no campo dos estudos literários. A convergência entre estas disciplinas aparece neste artigo de forma a situar o leitor sobre formas de expressão literária que não se esgotam na reflexão antropológica nem na averiguação proposta pelos estudos literários, mas se realizam na completude necessária entre essas áreas de conhecimento e a história.

O trabalho de verter os mitos para a língua portuguesa tem sido feito por antropólogos e especialistas na área de tradução, mas sua interpretação vem, aos poucos, tomando forma nas chamadas poéticas ameríndias, cuja manifestação poderá ser verificada nos trabalhos de Pedro de Niemayer Cesarino (2006), ao registrar mitos e cantos xamanísticos ameríndios; nas análises de cantos araweté feitas por 
Álvaro Faleiros (2012); na coleta e análise de cantos macuxi e taurepang feitas por Devair Antônio Fiorotti (2015); e também na investigação proposta por Eduardo Pires Rosse, no que denominará processos de microvariações nas poéticas ameríndias (2016). Não se pode negar ainda a importância de Roça barroca (2011), de Josely Viana Batista, ao traduzir o mito poético de criação do mundo dos mbyá-guarani.

Esta breve síntese de trabalhos que serviram, em alguma medida, de inspiração para este artigo não poderia prescindir de uma referência que nos parece fundadora, $O$ mármore e a murta: sobre a inconstância da alma selvagem (1992), de Eduardo Viveiros de Castro. Nesse artigo, a origem das reflexões se encontra no famoso Sermão do Espírito Santo, do Padre Antônio Vieira, quando o "imperador da língua portuguesa" compara o processo de conversão entre diferentes nações quanto à doutrina da fé. Há nações tenazes, mas que, uma vez rendidas à fé, não é preciso mais trabalhar com elas. Estas são as estátuas de mármore. Porém, não é este o caso dos índios que, semelhando estátuas de murta, embora moldáveis, logo perdem a forma que lhes foi dada. Nas palavras de Viveiros de Castro, empregando um símile vegetal menos europeu que a estátua de murta, "[os índios] eram como a mata que os agasalhava, sempre pronta a se refechar sobre os espaços precariamente conquistados pela cultura". Falando junto com Viveiros de Castro, é possível que essa inconstância da alma selvagem tenha corroborado para a preservação dos mitos aqui tratados ao mesmo tempo que a imersão dos povos indígenas amazônicos em pontos geograficamente cada vez mais inacessíveis ao branco tenha reforçado a preservação desses conhecimentos.

Por aí se vê que a convergência entre literatura e antropologia, entre literatura e história, entre literatura e tradução possibilita vasta reflexão sobre a poética de narrativas que, estando em grande parte ainda na oralidade, pouco a pouco são registradas, revelando mundos, preservando conhecimentos, inventariando diferentes línguas e aproximando culturas.

Seja talvez nesse ponto que as culturas se aproximam e, malgrado as formas de extermínio, poderemos pensar em quem haveremos de ser.

\section{Referências}

ALBUQUERQUE, Gabriel A. S. (2009) Brasil, Brasis: insulamento e produção literária no Amazonas. In: RIOS, Otávio. (Org.). O Amazonas deságua no Tejo: ensaios literários. Manaus: UEA. p. 49-60. 
BATISTA, Josely Viana (2011). Roça barroca. São Paulo: Cosac Naify.

CARTER, Angela (2007). 103 contos de fadas. Tradução de Luciano Viera Machado. São Paulo: Companhia das Letras.

CASTRO, Eduardo Viveiros (1996). Os pronomes cosmológicos e o perspectivismo ameríndio. Mana, Rio de Janeiro, v. 2, n. 2, p. 115- 144.

CASTRO, Eduardo Viveiros (2002). Perspectivismo e multinaturalismo na América indígena. In: CASTRO, Eduardo Viveiros. A inconstância da alma selvagem. São Paulo: Cosac Naify. p. 345-400.

CASTRO, Eduardo Viveiros de (1992). O mármore e a murta. Revista de Antropologia, São Paulo, v. 35, p 21-74.

CESARINO, Pedro de Niemeyer (2006). De duplos e estereoscópios: paralelismo e personificação nos cantos xamanísticos ameríndios. Mana, Rio de Janeiro, v. 12, n. 1, p. 105-135.

CURTIUS, Ernest Robert (1996). Literatura europeia e Idade Média latina. Tradução de Paulo Rónai e Teodoro Cabral. São Paulo: Edusp.

DESCOLA, Philippe (2001). Construyendo naturalezas: ecologia simbólica y práctica social. In: DESCOLA, Philippe; PÁLSSON, Gísli (Coord.). Naturaleza y sociedad: perspectivas antropologicas. México: Siglo Veintiuno. p.101-123.

FALEIROS, Álvaro (2012). Emplumando a grande castanheira. Estudos Avançados, São Paulo, v. 26, n. 76, p. 57-74.

FIOROTTI, Devair A. (2015). Os cantos indígenas Macuxi e Taurepang: possibilidades. Revista Philologus, ano 21, n. 63, p. 1.650-1.961, set./dez.

GARNELO, Luiza (2007). Cosmologia, ambiente e saúde: mitos e ritos alimentares Baniwa. História, Ciências, Saúde-Manguinhos, Rio de Janeiro, v. 14, supl., p. 191-212.

GARNELO, Luiza (2009). Comendo e bebendo entre os Baniwa. In: GARNELO, Luiza; GILDA, Baré. Comidas tradicionais indígenas do Alto Rio Negro. Manaus: Edua. p. 67-79.

GARNELO, Luiza et al (Org.) (2005). Cultura, escola, tradição: mitoteca na escola Baniwa. Manaus: Rasi/Ufam.

GARNELO, Luiza; DINIZ, Laise; SAMPAIO, Sully (2012). Experiências, eventos e lugares no mundo Baniwa. In: ANDRELLO, Geraldo (Org.). Rotas de criação e transformação. Narrativas de origem dos povos do rio Negro. São Paulo: ISA. v. 2, p. 90-101.

HILL, Jonathan; WRIGHT, Robin (1988). Rethinking history and myth. Urbana: University of Illinois Press.

KRÜGER, Marcos Frederico (2003). Amazônia: mito e literatura. Manaus: Valer. 
LEVI-STRAUSS, Claude (1975). A estrutura dos mitos. In: LEVI-STRAUSS, Claude. Antropologia estrutural. Rio de Janeiro: Tempo Brasileiro. p. 1237-266.

LEVI-STRAUSS, Claude (1978). Como morrem os mitos. In: LEVI-STRAUSS, Claude. Antropologia estrutural dois. Rio de Janeiro: Tempo Brasileiro. p. 261-276.

LEVI-STRAUSS, Claude (1993a). Relações de simetria entre ritos e mitos de povos vizinhos. In: LEVI-STRAUSS, Claude. Antropologia estrutural dois. Rio de Janeiro: Tempo Brasileiro. p. 244-260.

LEVI-STRAUSS, Claude (1993b). Mito e significado. Lisboa: Setenta.

ROSSE, Pires Eduardo (2016). Processos de microvariações nas poéticas ameríndias. Proa: Revista de Antropologia e Arte, Campinas, n. 6, p. 104-120.

VERNANT, Jean-Pierre (2005). O universo, os deuses, os homens. Tradução de Rosa Freire d'Aguiar. São Paulo: Companhia das Letras. p. 153.

WRIGHT, Robin (1993-1992). Umawali.Hohodene myths of the Anaconda, father of fish. Bulletin de la Société Suisse des Américanistes, Genebra, v. 57/58, p. 37-48.

WRIGHT, Robin M. (Org.) (1999). Waferinaipe Ianheke: a sabedoria dos nossos antepassados: histórias dos Hohodene e dos Walipere-Dakenai do rio Aiari. São Gabriel da Cachoeira: Foirn. (Coleção Narradores Indígenas do Rio Negro, v. 3).

ZUMTHOR, Paul (1993). A letra e a voz: a "literature" medieval. Tradução de Amálio Pinheiro e Jerusa Pires Ferreira. São Paulo: Companhia das Letras.

Recebido em 8 de março de 2017.

Aprovado em 17 de julho de 2017.

\section{resumo/abstract/resumen}

\section{Entre mundos: homens, serpentes e peixes em dois mitos baniwa}

Gabriel Albuquerque e Luiza Garnelo

As narrativas míticas indígenas coletadas e publicadas desde o século XIX têm se mostrado um campo fértil para discussões que se estabeleceram predominantemente na antropologia, mas também em áreas como a literatura. Aos poucos, os estudos literários vêm tomando parte nessa discussão, ampliando a pesquisa sobre narrativas orais e o lugar do mito nos escritos produzidos pelas populações indígenas amazônicas. Apoiado tanto nos estudos literários quanto em publicações da antropologia, o presente artigo busca 
interpretar dois mitos coletados da etnia Baniwa, versando sobre seu conhecimento e simbolizações do ambiente aquático e seus habitantes, bem como o caráter constitutivo das sociedades humanas que interagem com o domínio na alteridade na natureza.

Palavras-chave: mito, literatura, Baniwa, narrativas indígenas.

\section{Between worlds: men, serpents and fishes in two baniwa myths}

Gabriel Albuquerque e Luiza Garnelo

The mythical indigenous narratives collected and published since the 19th century have proved to be a fertile ground for discussions that have been established predominantly in Anthropology. Gradually, literary studies have been taking part in this discussion, expanding the research of oral narratives and the place of myth in the writings produced by Amazonian indigenous populations. Supported by both literary studies and anthropology, this article seeks to interpret two myths that compose the collection Culture, school, tradition: myth library at Baniwa School (2004).

Keywords: myth, literature, Baniwa indigenous narratives.

\section{Entre mundos: hombres, serpientes y peces en dos mitos baniwa}

Gabriel Albuquerque e Luiza Garnelo

Las narrativas míticas indígenas recolectadas y publicadas desde el siglo XIX se han mostrado como un campo fértil para discusiones que se establecieron predominantemente en la antropología, mas también en áreas como la literatura. Poco a poco, los estudios literarios vienen participando en dicha discusión, ampliando la investigación sobre narrativas orales y el lugar del mito en los escritos producidos por los pueblos indígenas amazónicos. Apoyado tanto en los estudios literarios como en publicaciones de la antropología, el presente artículo busca interpretar dos mitos recolectados de la etnia baniwa, examinando su conocimiento y las simbolizaciones del ambiente acuático y sus habitantes, que hacen parte de la recopilación Cultura, escola, tradição: mitoteca na escola Baniwa (2004).

Palabras clave: mito, literatura, narrativas baniwa. 